\title{
Undiagnosed depression among older adults living in a semi urban community in Southern Sri Lanka
}

\author{
Senadheera $C^{1}$, Pathirana KD ${ }^{2}$, Jayasekara KMSAK ${ }^{1}$, de Silva MLK $^{3}$, Dharmappriya $\mathrm{CKL}^{3}$ \\ ${ }^{\prime}$ Department of Psychiatry, ${ }^{2}$ Department of Medicine, Faculty of Medicine, University of Ruhuna, Galle, \\ Sri Lanka.
}

Correspondence: Dr. Chandanie Senadheera

e-mail: chandaniesenadheera@yahoo.co.uk

\begin{abstract}
Introduction: Depression is common in late life. Sri Lankan studies on depression in community living elderly are scarce. A sample of community living older people was assessed for presence of depressive symptoms.

Methods: Randomly selected 300 people aged above 50 years from Bope-Poddala MOH area who were not diagnosed with neurological illness, major psychiatric illness and not having severe visual or hearing impairment were screened using Geriatric Depression Scale-Sinhala version (GDS-S). Medical records were examined and diagnoses of non-communicable diseases were recorded;
\end{abstract}

Results: The majority were females $(\mathrm{n}=183,61 \%)$. The mean age was $62(\mathrm{SD}=8)$ years. Twenty nine percent of subjects were still working. Thirty six percent (males - $40 \%$ and females - $36 \%$ ) had sought medical treatment for non-communicable diseases.

Twenty five participants ( $10 \%$ of males , $7 . \%$ of females) met criteria for depression (GDS-S score $>=6$ ). Nine percent of those who were aged 50-64 years and $7.4 \%$ of those who were older than 64 years were found to have depressive symptoms.

Conclusions: One in 12 older adult showing depressive symptoms signals the need of professional attention to the mental health well-being of older adults. As one in three of these people already attend health care services for their medical problems, these services can provide assessment of depression to make appropriate referrals/ interventions.

Keywords: Depression, GDS, older adults

\section{Introduction}

World Health Organisation has ranked depression as the $4^{\text {th }}$ leading cause of disability worldwide (1) and projects that by 2020 it will become the $2^{\text {nd }}$ leading cause (2). Depression is common in late life. According to Blazer it affects nearly 5 million of 31 million Americans aged 65 years or more (3). Furthermore, major depression is reported in $8-16 \%$ of community dwelling older adults. Prevalence of depression among Sri Lankan older population is not known. A study in Colombo district has found that lifetime prevalence of depression in that sample $(6.6 \%)$ is lower compared to that $(16.6 \%)$ in the USA (4). Depression is associated with functional and cognitive decline affecting person's quality of life. The patient and the family may fail to recognise it as an illness as symptoms of depression could be misinterpreted as signs of ageing. If untreated, depression could cause impairment in different spheres of life resulting in delayed recovery from medical illnesses and increased risk of suicide. 
According to the World Bank, Sri Lanka has the fastest ageing population in South Asia (5). It also reveals that country's share of population over 60 years old in 2000 was $9.2 \%$ which will reach almost $30 \%$ by 2050 . With growing number of elderly population in the country, health authorities need to plan services to cater for increasing needs. Studies on elderly depression will help to enhance services to improve mental well-being of the elderly.

The Geriatric Depression Scale (GDS) has been specifically designed to measure depression in older population (6). The shorter form of GDS with 15 items (GDS-15) has been widely used for research and clinical purposes as a time saving and acceptable substitute for 30 item GDS $(7,8)$. The 15 item GDS has been validated for Sri Lankan clinical population and it is culturally acceptable and easy to administer in outpatient settings in Sri Lanka (9). While English version of GDS-15 has the cutoff score of 5, cutoff value of GDS-S has been set as 8 with both specificity and sensitivity of $73.3 \%$.

There are studies on prevalence of depression among different Sri Lankan populations. Study of patients aged 65 years and above admitted to National Hospital Sri Lanka (NHSL) found that $40 \%$ of the study sample have depression (10). In another study involving 100 subjects over 65 years of age admitted to NHSL found that over $60 \%$ of the sample met criteria for depression (11). A study on outdoor patients presented to the same hospital showed the prevalence of depression as $22.4 \%$ (12) However, in this study, the rate of prevalence was lower in older age group (above 61 years) compared to their younger counterparts (aged below 30 years). Other studies have also reported high prevalence of depression in patients with chronic illnesses $(13,14)$. Two community studies in Sri Lankan involving older adults report high prevalence of depression; one study which included predominantly a Sinhalese subjects has reported the prevalence rate of $27.8 \%$ (15) while the other study which included all three major ethnic groups reported the rate of $31.8 \%$ (16).

We screened an older population in a semi-urban community as a part of a larger study and in this paper we present data in relation to the presence of depressive symptoms in the sample which was screened.

\section{Methods}

We conducted a door to door survey and screened randomly selected people aged between 50 and 79 years from the Bope-Poddala Medical Officer of Health $(\mathrm{MOH})$ area in Galle district. Those who had neurological illness, major psychiatric illness and severe visual or hearing impairment were excluded. A total of 300 individuals who met selection criteria and provided consent for the study were requested to fill the GDS-S. Those who indicated difficulty in filling the questionnaire due to the lack of literacy or due to visual problems were helped by the research assistants. Participants' medical records were perused and the presence of diabetes, hypertension, dyslipedaemia and ischaemic heart disease was recorded.

GDS-S score ranges from 0 to 15 . In order to compare presence of depression in our sample with that in other Sri Lankan samples, we considered the cut off as 6 . In our literature search two studies using GDS-15 in Sri Lankan community samples were found and in both studies a score of 6 or more has been considered as a suitable threshold $(15,16)$. We did not use the cut-off of the validation study (9) as it has been validated for a clinical sample.

Our study was approved by the Ethical Review Committee of Faculty of Medicine, University of Ruhuna.

\section{Results}

The majority were females $(n=183,61 \%)$. The mean age was $62(\mathrm{SD}=8)$ years. Twenty eight percent of participants were still working. Majority of the participants $(83 \%)$ were living with spouse and 37 were widowed. Furthermore, 94\% reported that they handled money and 97\% reported as actively involved in household activities. Thirty six percent of participants $(n=107)$ had sought medical treatment for one or more of the following conditions: diabetes, hypertension and dyslipidaemia and ischaemic heart disease. This group consisted of $40 \%$ of males and $36 \%$ of females. Forty three percent of the older age group(aged above 64 years) had one or more of those conditions against $30.7 \%$ of their younger counterparts $(p=0.03)$. Table 1 shows demographic and clinical characteristics of the sample. 
Table 1: Demographic and clinical characteristics of the sample

\begin{tabular}{|c|c|}
\hline Characteristic & Total $=300$, Number $(\%)$ \\
\hline \multicolumn{2}{|l|}{ Age (in years) } \\
\hline $50-64$ & $179(60)$ \\
\hline $65-79$ & $121(40)$ \\
\hline \multicolumn{2}{|l|}{ Sex } \\
\hline Female & $183(61)$ \\
\hline Male & $117(39)$ \\
\hline \multicolumn{2}{|l|}{ Educational level } \\
\hline Up to 5 years & $30(10)$ \\
\hline 6 to 10 years & $180(60)$ \\
\hline More than 10 years & $89(30)$ \\
\hline \multicolumn{2}{|l|}{ Employment status } \\
\hline Employed & $84(28)$ \\
\hline Retired / Not working & $122(41)$ \\
\hline Never worked & $92(30)$ \\
\hline \multicolumn{2}{|l|}{ House-hold monthly income } \\
\hline Up to Rs. 10,000 & $130(43)$ \\
\hline Rs. 10,000 to Rs. 20,000 & $101(34)$ \\
\hline More than Rs. 20,000 & $69(23)$ \\
\hline \multicolumn{2}{|l|}{ Non-communicable diseases } \\
\hline Diabetes & $40(13)$ \\
\hline Hypertension & $73(24)$ \\
\hline dyslipidaemia & $33(11)$ \\
\hline Ischaemic heart disease & $18(06)$ \\
\hline
\end{tabular}

GDS-S score of the sample ranged from 0 to 13 . A total of $25(8.3 \%)$ subjects met criteria for depression. This group included $10.3 \%$ of males $(n=12)$ and $7.1 \%(n=13)$ females. We used cross tabulation to compare some demographic and clinical characteristics between two subgroups; those who met criteria for depression and those who did not. These data are summarised in Table 2. The proportion of subjects with GDS-S score 6 or above was less than $10 \%$ in each of the both age groups; i.e. those who were between 50 - 64 years of age and those who were above 64 years.
We failed to detect statistically significant associations between demographic variables and presence of GDS criteria for depression. Twenty four percent $(n=6)$ of those who met criteria for depression had been diagnosed with one or more of the non-communicable disease we recorded. Statistically non-significant difference was observed between subjects with one or more noncommunicable diseases and those without, in relation to presence of depression $(5.6 \%$ versus $9.9 \%$ respectively). 
Table 2: Associations of GDS-S score with demographic and clinical characteristics of the sample

\begin{tabular}{|c|c|c|c|c|}
\hline & & $\begin{array}{c}\text { GDS-S score } \geq 6 \\
\text { n }(\%)\end{array}$ & $\begin{array}{c}\text { GDS-S score }<6 \\
\text { n (\%) }\end{array}$ & $p$ value \\
\hline \multirow[t]{2}{*}{ Age } & $50-64$ years & $16 \quad(9 \%)$ & $162 \quad(91 \%)$ & 0.63 \\
\hline & $65-79$ years & $9(7.4 \%)$ & $112(92.6 \%)$ & \\
\hline \multirow[t]{2}{*}{ Gender } & Male & $12(10.3 \%)$ & $104(89.7 \%)$ & 0.32 \\
\hline & Female & $13(7.1 \%)$ & $170(92.9 \%)$ & \\
\hline \multirow[t]{2}{*}{ Education } & Upto $\mathrm{O} / \mathrm{L}$ & $19(9.1 \%)$ & $190(90.9 \%)$ & 0.50 \\
\hline & Above $\mathrm{O} / \mathrm{L}$ & $6(6.7 \%)$ & $83(93.3 \%)$ & \\
\hline \multirow[t]{2}{*}{ Monthly Income } & Upto Rs. 10,000 & $14(10.9 \%)$ & $115(89.1 \%)$ & 0.17 \\
\hline & $>$ Rs. 10,000 & $11(6.5 \%)$ & $159(93.5 \%)$ & \\
\hline \multirow[t]{2}{*}{ Employment status } & Working & $9(10.8 \%)$ & $74(89.2 \%)$ & 0.35 \\
\hline & Not working & $16(7.5 \%)$ & $198(92.5 \%)$ & \\
\hline \multirow[t]{2}{*}{ *Diseases } & Present & $6(5.6 \%)$ & $101(94.4 \%)$ & 0.19 \\
\hline & Absent & $19(9.9 \%)$ & $173(90.1 \%)$ & \\
\hline
\end{tabular}

* One or more of the following conditions; diabetes, hypertension, dyslipidaemia and ischaemic heart disease

\section{Discussion}

Our study found that one in every twelve older adults living in a semi-urban community show depressive symptoms. Two available community based studies conducted on the prevalence of depression among older Sri Lankan populations report higher prevalence rates (more than 25\%) compared to the present study. This difference could be due to sample selection criteria; our sample was comparatively functional older adults free of severe physical disabilities or major neurological or psychiatric conditions. A population based survey in a sample aged 15 years and above living in Colombo district found that life time prevalence of depression is $6.6 \%$, rising up to $11.2 \%$ if functional impairment criterion was excluded (4). Comparing our findings with the prevalence reported in this study is not appropriate due to notable difference in the age of the study samples. Moreover, the variations in prevalence rates reported by different studies could be due to the differences in the instruments used to detect depression.

It is known that depression is common among females and the risk for depression increases with age. However we failed to find associations between demographic variables and presence of depression. It could be due to the small sample size and also sample selection biases.

Studies involving older patients report high prevalence rates of depression ranging from $22.4 \%$ to $60 \%(11,12)$. However our study sample comprised of comparatively healthy older adults due to exclusion criteria we used. Furthermore, a large majority of the study participants were actively involved in their house-hold activities. Therefore our finding that $8.3 \%$ of comparatively healthy community living older adults having depressive symptoms signals the need of professional attention to the well-being of older population. It also underscores the importance of community studies to explore depressive symptoms in elderly in large and more inclusive samples.

As one in every three of these people are already in contact with health care services for their medical problems, these services can provide assessment of depression to make appropriate referrals/ interventions to improve the mental health wellbeing of older adults. However the evidence from elsewhere indicates that depression is underdiagnosed in primary care settings (17). 
None of the participant, who met criteria for depression, had approached psychiatric services. It could be due to misinterpretation of depressive symptoms as signs of ageing by these individuals and their families. It may indicate the need for mental health awareness raising programmes targeting general public.

Our study is not without limitations; relying on a self-administered questionnaire to detect depressive symptoms especially when the sample consists of $10 \%$ of participants only with primary education is a major limitation. Although we assisted these people by reading out the items and marking their responses, the written language used in the scale could be complicated for them. The other limitation is our sample selection criteria; we studied comparatively healthy older adults from a semiurban area. Therefore our findings cannot be generalised for Sri Lankan older population.

\section{Acknowledgements}

We wish to thank all the participants of our study and TURIS project of University of Ruhuna (Grant No. APW/SRL/HRH/001/RB/07/ER/1.1.9) for funding the study.

\section{References}

1. Murray CJ, Lopez AD. Evidence based health policylessons from the Global Burden of Disease Study. Science 1996; 274: 740-43.

2. Murray CJ, Lopez AD, eds. The Global Burden of Disease: a comprehensive assessment of mortality and disability from diseases, injuries and risk factors in 1990 and projected to 2020. Cambridge, Harvard School of Public Health on behalf of the World Health Organization and the World Bank; 1996.

3. Blazer DG. Depression in late life; review \& commentary. FOCUS 2009; 7(1): 118-36.

4. Ball HA, Siribaddana SH, Kovas Y, et al. Epidemiology and symptomatology of depression in Sri Lanka: A crosssectional population-based survey in Colombo District JAffect Disord 2010 Jun; 123(1-3): 188-96.

5. Sri Lanka Aging Survey (SLAS), the survey based on a representative sample of Sri Lankan people. World Bank; 2006. [http://siteresources.worldbank.org/INTSILANKA/ Resources/LKAgingEXxSum.pdf\}]
6. Yesavage JA, Brink TL, Rose TL. Development and validation of a geriatric depression screening scale: a preliminary report. J Psychiatr Res 1982-1983; 17(1): $37-49$.

7. Sheikh JI, Yesavage JA. Geriatric depression scale (GDS): Recent evidence and development of a shorter version. Clinical Gerontologist 1986; 5: 165-73.

8. Lesher EL, Berryhill JS. Validation of the geriatric depression scale-short form among inpatients. Journal of Clinical Psychology 1994; 50: 256-60.

9. Kulathunga M, Umayal S, Somaratne S, et al. Validation of the Geriatric Depression Scale for an elderly Sri Lankan clinic population. Indian J Psychiatry 2010; 52(3): 254-6.

10. Weerasuriya $\mathrm{N}$, Jayasinghe S. A preliminary study of the hospital-admitted older patients in a Sri Lankan tertiary care hospital. Ceylon Medical Journal 2005; 50(1): 18-10.

11. Rodrigo C, Perera S, Adhikari M. et al. Cognitive impairment and symptoms of depression among geriatric patients in a tertiary care unit in Sri Lanka. Indian Journal of Psychiatry 2010; 52(3), 279-8, 2010.

12. Anandakumar D, Ratnatunga SS, Dayabandara M, Hanwella R, de Silva VA. Depressive disorder in patients attending the outpatient department of a tertiary care hospital in Colombo. Ceylon Medical Journal 2010; 61(3): 118-22.

13. Ketharanathan T, Hanwella R, Weerasundera R, de Silva VA. Major depressive disorder in Parkinson's disease: a cross-sectional study from Sri Lanka. BMC Psychiatry 2014; 14: 278.

14. Sumanatissa M, De Silva VA, Hanwellla R. Prevalence of major depressive episode among patients with pre dialysis chronic kidney disease. Int J Psychiatry Med 2011; 41: 47-56.

15. Malhotra R, Chan A, Otsbye T. Prevalence and correlates of clinically significant depressive symptoms among elderly people in Sri Lanka: Findings from a national survey. Int Psychogeriatr 2010; 22: 227-36.

16. Khaltar A, et al. Depression among older people in Sri Lanka: with special reference to ethnicity. Geriatr Gerontol Int 2017; 1-7.

17. Cepoiu M, McCusker J, Cole MG, Sewitch M, Belzile E, Ciampi A. Recognition of depression by non-psychiatric physicians - A systematic literature review and meta analysis. JGen Intern Med 2008; 23: 25-36. 